\title{
La captura del Estado
}

Francisco Durand (2019). La captura del Estado en América Latina. Reflexiones teóricas. Lima: OxFAM, Fondo Editorial de la Pontificia Universidad Católica del Perú.

NiCOLÁS LYNCH

Universidad Nacional Mayor de San Marcos

Francisco Durand ha escrito un libro notable, La captura del Estado en América Latina. Reflexiones teóricas. Su argumento es que el Estado en el mundo, y particularmente en América Latina, ha sido capturado por las grandes corporaciones, nacionales y multinacionales, poniéndolo a su servicio. Lo importante, además, es que no se trata de una reflexión puramente teórica, sino de la culminación, quizás todavía parcial, de un largo trabajo de investigación sobre el tema que abarca por lo menos media docena de libros.

Su tesis central es que la concentración del poder económico por las grandes corporaciones, su correlato en la hiperconcentración del poder político desconectado de la población y el debilitamiento de la sociedad civil, son los grandes factores que permiten esta captura. Todo ello producido en una época de globalización neoliberal en la que se hace aparecer este proceso como el único posible y el pensamiento que desarrolla como las ideas exclusivas y excluyentes de nuestro tiempo.

Pero lo interesante del libro es que no se queda en señalar los grandes factores, que podríamos llamar estructurales, sino que pasa a describir los instrumentos de esta captura. Así, Durand nos refiere a la financiación electoral, el lobby, la puerta giratoria y los sobornos, señalando que se trata de un proceso caracterizado por la opacidad, las sombras, como el ámbito preferido de las grandes corporaciones para actuar. Asimismo, Durand establece un ciclo político diferenciado en tres fases: electoral, ministerial y de políticas públicas, en las que se usan preferentemente la financiación electoral, el lobby, la puerta giratoria o el soborno para actuar. Por último, señala que el más importante de 
todos estos instrumentos es la financiación electoral, porque en las democracias es el origen de los Gobiernos que se aspira a capturar.

Como buen libro de teoría política, se desarrolla en contrapunto con otros enfoques teóricos, en especial con el liberal pluralista. Este enfoque establecido en la ciencia política de los Estados Unidos por Robert Dahl, en un momento temprano de su carrera (1956) y desmentido por el mismo autor treinta años más tarde (1985), por las mismas debilidades que le encuentra Durand, es ampliamente rebatido por este último con las evidencias de la crisis neoliberal. Los pluralistas originales planteaban que el poder estaba repartido en la sociedad de tal manera que tanto las grandes empresas como los ciudadanos de a pie tenían una porción del mismo, bastando con alguna regulación para equilibrar fuerzas. Los embates de Wright Mills (1956) y Steven Lukes (2005), en sus reflexiones sobre las elites y la naturaleza del poder, trajeron abajo el edificio liberal pluralista, en cuyos escombros hurga Francisco Durand para nuestra región encontrando que no explica casi nada en esta realidad. Por ello, su reflexión más importante al respecto es que no se trata del análisis del Gobierno para entender el régimen político, sino del poder y que este último no reside necesariamente en las instituciones democráticas, sino principalmente en los directorios de las grandes empresas.

Para terminar, una nostalgia. Lo que sí extraño en el texto es una relación más explícita y elaborada con la teoría marxista del Estado, tan invisibilizada en esta época y hasta negada por algunos (Bobbio 1987), pero de la cual Francisco Durand es necesariamente tributario. Si tomamos la síntesis de Fred Block (1987) sobre el tema, tenemos tres versiones, quizá momentos distintos de reflexión marxista sobre la cuestión: el instrumental, el de la autonomía relativa y el estructural. Los dos primeros señalados por Marx y Engels en el Manifiesto del Partido Comunista (1848), también por Marx en El dieciocho de brumario de Luis Bonaparte (1851), y el último por Nicos Poulantzas en Poder político y clases sociales en el Estado capitalista (1969). Francisco Durand audazmente refiere su reflexión al primer momento, el instrumental, quizá si el más criticado en el siglo XX de la teoría marxista, en el que MarX y Engels señalan que el Estado es el directorio de los intereses de la clase dominante. Al optar aquí sí de manera explícita por la definición germinal, Durand no solo opta por alguna definición sino también por una actualización de época. En los tiempos de hegemonía neoliberal, con el Estado capturado, las reflexiones sobre el Estado que se produjeron a la luz de la modernidad de entreguerras, e incluso las posteriores del Estado de bienestar en la segunda 
mitad del siglo XX, quedan como construcciones de un momento anterior o en el mejor de los casos paralelo. Sin embargo, lo que parecía imposible cuando nos formamos en teoría política cuarenta años atrás, analizando las diferencias entre la sociedad y el Estado como características clave de lo moderno en la política, parecen dejarnos en aras de un poder tentado por un absoluto que nos controla.

¿Llegaremos al poder absoluto de las grandes corporaciones que nos controlen por siempre? Ojalá que no. Lo que devela Francisco Durand puede ayudarnos a ello. 